\title{
EXPERIMENTAÇÃO NA EDUCAÇÃO QUÍMICA: ELABORAÇÃO DE SINAIS EM LIBRAS PARA PRÁTICAS DE LABORATÓRIO
}

\section{EXPERIMENTATION IN CHEMICAL EDUCATION: ELABORATION SIGNALS IN LIBRAS FOR LABORATORY PRACTICES}

\author{
Geilson Rodrigues da Silva ${ }^{1}$ \\ Talina Meirely Nery dos Santos ${ }^{2}$ \\ Griscele Souza de Jesus ${ }^{3}$ \\ Lucas Pereira Gandra ${ }^{4}$
}

\begin{abstract}
Resumo: A Química é uma Ciência com poucos sinais específicos em Língua Brasileira de Sinais para o ensino de pessoas com surdez. Essa barreira de linguagem pode ocasionar obstáculos de aprendizagem aos estudantes surdos. Sendo assim, a presente pesquisa teve como objetivos catalogar verbetes e criar sinais para a utilização em aulas práticas de Química. Para coleta de dados foram levantados os termos na literatura no dicionário ilustrado trilíngue que possuíssem relações com a disciplina de Química, ao qual foram categorizados a partir da Análise de Conteúdo, em função do seu emprego e utilização. Realizou-se a análise quantitativa dos termos mais presentes em roteiros de aulas experimentais, usadas na disciplina de Química Geral e Experimental Ida Licenciatura em Química do IFMS campus Coxim. Sendo elaborados quatro sinais de instrumentos do laboratório de Química que apresentam potencial para serem utilizados em práticas bilíngues, no ensino superior e médio.
\end{abstract}

Palavras-chave: Educação Bilíngue; Formação de Conceitos Científicos; Práticas Experimentais.

\begin{abstract}
Chemistry is a Science with few specific signs in Brazilian Sign Language for teaching deaf people. This language barrier can lead to learning obstacles for deaf students. Thus, the present research had as objectives to catalog entries and to create signals for the use in practical classes of Chemistry. In order to collect data, the terms in the literature in the trilingual illustrated dictionary that had relations with the discipline of Chemistry were categorized from the Content Analysis, according to their use and use. A quantitative analysis of the most present terms was carried out in experimental classes, used in the General Chemistry and Experimental I subject of the Chemistry Degree of the IFMS campus Coxim. Four signs of chemistry laboratory instruments are being developed, which have the potential to be used in bilingual practices in higher and secondary education.
\end{abstract}

Keywords: Bilingual Education; Formation of Scientific Concepts; Experimental Practices.

\footnotetext{
${ }^{1}$ Licenciado em Química pelo Instituto Federal de Mato Grosso do Sul (IFMS). Mestrando em Ensino de Ciências pela Universidade Federal de Mato Grosso do Sul (UFMS). Campo Grande, Mato Grosso do Sul, Brasil.E-mail: geilsonrodrigues367@gmail.com

${ }^{2}$ Licenciado em Química pelo Instituto Federal de Mato Grosso do Sul (IFMS). Mestrando em Ensino de Ciências pela Universidade Federal de Mato Grosso do Sul (UFMS). Campo Grande, Mato Grosso do Sul, Brasil. Email: talina meirely@ hotmail.com

${ }^{3}$ Graduada em Pedagogia com habilitação nos anos iniciais do Ensino Fundamental pela Universidade Federal de Mato Grosso do Sul (UFMS). Mestranda Em Ensino de Ciências pela UFMS. Professora do Instituto Federal de Mato Grosso do Sul (IFMS), Jardim, Mato Grosso do Sul, Brasil. E-mail: griscele.jesus@ifms.edu.br

${ }^{4}$ Licenciado em Química pelo Instituto Federal de Mato Grosso do Sul (IFMS). Mestrando em Ensino de Ciências pela Universidade Federal de Mato Grosso do Sul (UFMS). Professor da Fundação Educacional de Coxim, da E.E. Viriato Bandeira. Responsável Técnico e Tutor de Aulas Práticas da UNOPAR-Pólo Coxim. Coxim, Mato Grosso do Sul, Brasil. E-mail: luca.gandra@ hotmail.com
} 


\section{Introdução}

A legislação brasileira realizou avanços significativos a respeito da educação de pessoas surdas, e teve como ponto culminante a Lei Federal no 10.436 , de 24 de abril de 2002, que reconheceu a Língua Brasileira de Sinais - LIBRAS como instrumento legítimo de comunicação e expressão. O documento ainda determina que sejam garantidas formas institucionalizadas de apoiar seu uso e difusão, bem como, a obrigatoriedade da disciplina de LIBRAS na grade curricular dos cursos de licenciatura e de fonoaudiologia, sendo eletiva nos demais cursos superiores (BRASIL, 2007).

Somando-se a isso, o Governo Federal promulgou o Decreto $n^{\circ} 5.626 / 05$, que teve como objetivo regulamentar a Lei $\mathrm{n}^{\mathrm{o}} 10.436 / 2002$, tendo como metas, dispor acerca da formação e a regulamentação do professor, instrutor e tradutor/intérprete de LIBRAS. Apesar da evolução da legislação em relação à educação de pessoas surdas, as escolas públicas ainda utilizam a presença do intérprete em sala de aula como a única ferramenta de integração dos estudantes surdos (STUMPF; QUADROS, 2010).

Sendo assim, a Educação Inclusiva apresentou avanços em relação à superaçãodo método do oralismo utilizado nos primórdios da Educação de Surdos, permitindo maior inserção desses estudantes nas aulas regulares. Entretanto, Botelho (1998); Quadros e Schmiedt (2006) afirmaram que os discentes surdos, não compartilham uma língua oral com seus colegas e professores, ficando em desvantagem linguística em sala de aula, sem garantia de acesso aos conhecimentos científicos e tecnológicos.

Dessa forma, Fernandes (2005) defendeu que a única proposta realmente efetiva para o ensino de alunos surdos, trata-se da Educação Bilíngue que contrapõe o modelo oralista, pois considera o meio visual/gestual fundamental para a aquisição da linguagem do surdo, opondo-se ao método da comunicação total e defendendo o espaço efetivo da Língua de Sinais. Ainda nessa linha, o autor considerou que os estudantes surdos recebessem sua instrução em duas línguas, considerando a Língua de Sinais como materna e, a partir desse pressuposto, uma segunda língua que no caso do Brasil é a Língua Portuguesa, ensinada na modalidade escrita.

Os autores Góes (1996) e Fernandes (2003) especificaram que a Educação de Surdos na perspectiva bilíngue transcende as questões linguísticas, indo além da Língua de Sinais e da Língua Portuguesa. Esta modalidade de Educação situa-se no contexto de garantia do acesso e permanência na escola dos discentes surdos. Taveira (2014) concorda com os autores ao apontar que a escola bilíngue é defendida pelos movimentos dos surdos, 
como sendo o marco fundamental da consolidação de uma educação em um país que se entende equivocadamente monolíngue. Somente com esta organização escolar, o bilinguismo contemplará as dimensões sociais, científicas e tecnológicas. Logo, observase que a Educação Bilíngue representa um meio de buscar a recuperação do direito dos estudantes surdos a Língua de Sinais, levando em consideração o contexto social e cultural no qual estão inseridos.

Entretanto a Educação Bilíngue no Brasil possui diversos entraves para avançar no contexto da Educação em Ciências e mais especificamente naEducação Química, pois uma das principais dificuldades trata-se da ausência de diversos sinais para o Ensino de Química, conforme relatos de Sousa e Silveira (2011). Em seus estudos esses autores identificaram a existência de poucas terminologias em LIBRAS, para descrever os fenômenos químicos e os conceitos científicos específicos, sendo assim, apontaram que os intérpretes enfrentam dificuldades com determinadas especificidades dos conteúdos, uma vez que nem sempre o conhecimento desses profissionais condiz com o conceito que está sendo trabalhado, de modo que a tradução para LIBRASpode ocorrer de forma equivocada.

Para Lacerda (2006) em virtude da ausência de terminologias principalmente relacionadas às áreas científicas, os intérpretes encontram-se realizando traduções defasadas, uma vez que à falta de sinais leva esses profissionais a realizarem a tradução de palavra por palavra, provocando uma defasagem temporal em relação à tradução e à fala do professor, podendo ocasionar obstáculos de aprendizagem nos discentes surdos.

Como os conhecimentos científicos desenvolvidos são produzidos em uma língua diferente da materna dos estudantes surdos, as práticas bilíngues são favoráveis nesse contexto, pois inserem os discentes surdos na discussão do avanço da Ciência e da Tecnologia. Ao qual, contribuem para o diálogo entre saberes, permitindo, o acesso a esses tópicos, que são indispensáveis para a compreensão das diferentes realidades no plano da natureza, da sociedade, da cultura e da vida (BRASIL, 1999).

Sendo assim, devido à relevância da Educação Bilíngue para Surdos, em consonância com a escassez de sinais em LIBRAS para a disciplina de Química, tiveramse como objetivos:catalogar verbetes da Ciência Química em um dicionário Trilíngue; analisar quantitativamente, os termos mais frequentes em roteiros experimentais de Química; e criar os principais sinais que aparecem nos roteiros, mas estão ausentes no dicionário para a utilização em aulas práticas na disciplina de Química. 


\section{Experimentação na Educação Química}

A escolha pela temática "Química Experiemental” para catalogação e criação dos sinais, foi feita tendo em vista o entendimento de que a experimentação contribui para que os discentes desenvolvam a capacidade de argumentação científica que na visão de Lauxen et al (2017), leva a formulação do pensamento analítico, sistemático pautado em teorias que contemplam o desenvolvimento da ciência em diferentes óticas. Além disso, Garcia et al (2012), defende que a argumentação científica estruturada nas atividades experimentais propicia o desenvolvimento de interpretações dos vários modelos explicativos utilizados para elucidar os fenômenos investigados, permitindo uma visão do processo de construção de conceitos científicos. Essa concepção possibilita o aperfeiçoamento das habilidades cognitivas para a investigação dos fenômenos naturais em distintas situações.

Um outro aspecto que podemos considerar que emergem das atividades experimentais trata-se das habilidades investigativas, que é defendida como o eixo norteador da compreensão dos conceitos científicos, de forma a superar o ensino tradicional. Nessa vertente os problemas surgem do cotidiano dos discentes e com isso os conhecimentos dos mesmos são valorizados (AZEVEDO, 2004).

Contribuindo com essa discussão Guedes (2010) relatou que o ensino experimental, constitui-se o ambiente propicio para o desenvolvimento das seguintes habilidades investigativas: curiosidade, iniciativa, criatividade, criticidade, bem como, o raciocínio abstrato, que são mobilizadas para apresentar soluções para o problema, que irá atuar na estrutura cognitiva, permitindo produzir infêrencias que levará os discentes a serem mais autônomos e engajados nos problemas propostos. Esse autor ainda afirmou que as atividades experimentais investigativas devem estar pautadas em situações problemas, para serem potencialmente significativas na aprendizagem dos discentes.

Por sua vez as situações problemas empregadas nas atividades experimentais investigativas, só são efetivas, ao englobar fatores que contemplem a demonstração de fenômenos aliados a conceitos teóricos, assim como, devem permitir que os estudantes compreendam o método científico, para que coletem dados de forma sistemática, testem hipóteses, observem a realidade e apresentem domínio dos instrumentos de laboratório (HODSON, 1988).

Com o desenvolvimento de atividades experimentais, é possível ainda permitir que os discentes compreendam como o conhecimento químico é construído, ressaltando 
os aspectos de funcionamento dessa ciência a partir de diferentes vertentes que são dispostas para criar oportunidades dos estudantes compreendê-las e transformá-las ao longo das aulas evoluindo para concepções de modelos científicos mais abrangentes. Sendo possível estabelecer paralelos entre o processo de ensino e aprendizagem, de forma semelhante ao desenvolvimento da própria Química (LIMA; NÚÑEZ, 2011).

Já Giordan (1999), considera a utilização da experimentação, como uma estratégia para o desenvolvimento do senso crítico e das habilidades de investigação da Natureza da Ciência nos estudantes. Ferreira, Hartwig e Oliveira (2010), por sua vez corroboram com essas afirmações e acrescetam que a experimentação deve ser utilizada em todos os níveis educacionais, pois constitui-se uma ferramenta didática que auxilia os docentes na construção de conceitos científicos para os discentes, contribuindo na aprendizagem.

Concordamos com os aportes apresentados acima acerca do processo de investigação experimental e seu potencial, para propiciar o aprendizado dos discentes surdos e ouvintes. Entretanto, para isso é necessário à utilização de aparatos do laboratório de Química, cuja Educação Bilíngue requer o uso de sinais para tais equipamentos, justificando assim, a realização desta pesquisa.

\section{Metodologia}

A pesquisa teve início com a catalogação de verbetes do Dicionário Enciclopédico Ilustrado Trilíngue da Língua de Sinais Brasileira, de Capovilla e Raphael (2009). A opção pela utilização desse material se deu por este conter uma proposta lexicográfica em três línguas: Português, Inglês e Libras, assim como, uma série de verbetes científicos e tecnológicos, ou seja, trata-se de um dicionário manual descritivo-explicativo (FAULSTICH, 2006).

Para organização dos verbetes catalogados a partir do dicionário, utilizou-se da Análise de Conteúdo de Bardin (2009), mais especificamente a Categorização. A análise de conteúdo tem uma organização bem definida, e que preza por três etapas que são respectivamente: a pré-análise (leitura flutuante dos dados); a exploração do material (definição de categorias/sistema de codificação); e o tratamento dos resultados (inferência e interpretação).

Sendo assim, após a realização dos procedimentos analíticosda Análise de Conteúdo, foram criadas três categorias (Termos empregados pelos estudantes em 
contextos do cotidiano; Conceitos que envolvem experimentos simples; Equipamentos de laboratório).

Em seguida, foi selecionado o Caderno de aulas práticas da disciplina de Química Geral e ExperimentalI, desenvolvido de acordo com o Projeto Pedagógico do Curso de Licenciatura em Química (IFMS, 2016), no qual aponta a importância de se trabalhar noções de segurança em laboratório de Química, além da utilização dos equipamentos e vidrarias básicos de um laboratório; introdução às técnicas básicas de trabalho em laboratório de Química: pesagem, dissolução, medidas de volume, filtração. Essas técnicas possibilitam que a experimentação possa ser utilizada como ferramenta didática para a discussão de situações problemas do cotidiano, contextualizando e permitindo o estímulo das atividades investigativas no âmbito da disciplina de Química (GUIMARÃES, 2009). A partir desse material se realizou um agrupamento de cunho quantitativo no que tange aos verbetes mais frequentes nos roteiros.

A partir disso, foram selecionados quatro verbetes, pela contagem frequencial de ocorrência dos mesmos nos roteiros experimentais, para o desenvolvimento dos sinais, comparando as terminologias expressas nos roteiros com as categorias obtidas na análise da enciclopédia.

Para a elaboração dos sinais utilizou-se dos saberes referentes ao núcleo estudante surdo/intérprete/docente (SOUSA; SILVEIRA, 2011). Sendo que os sinais foram desenvolvidos por um estudante surdo acadêmico do curso de Licenciatura em Química, que teve dificuldade para compreender os conceitos da disciplina de Química, durante as aulas experimentais, devido à ausência de sinais específicos para os fenômenos físicoquímicos, bem como, para as vidrarias do laboratório.

A criação dos sinaisfoi auxiliada pelo intérprete e pelo docente, no tocante aos conhecimentos científicos. E o estudante surdo seguiu-se as orientações de Vargas (2014) que são: configuração de mão, movimento, orientação das mãos, ponto de articulação e expressão facial/corporal.

A configuração que as mãos devem assumir para a produção dos sinais, está de acordo com as posições que as mãos assumem para elaborar os sinais que representam o alfabeto. Os sinais podem apresentar um movimento ou não, esses movimentos são classificados em: internos à mão; movimentos do pulso; movimentos direcionais no espaço ou ao corpo. As orientações das mãos refletem a direção que a palma da mão aponta na produção do sinal. Utiliza-se das direções para cima, para baixo, para frente, para trás ou para a direita ou para a esquerda. Os sinais podem ter um sentido em uma 
direção, e a inversão de sentido, representa uma ideia de oposição. Em relação a articulação, os sinais podem ser articulados no espaço, ou tocando alguma parte do corpo. Por fim, a expressão facial e/ou corporal, envolve os movimentos do corpo e da face (VARGAS, 2014).

\section{Resultados e Discussões}

Com o desenvolvimento da primeira etapa da pesquisa foi obtido no dicionário trilingue um total de sessenta e dois verbetes referentes a conteúdos de Química que, após a leitura flutuante, foi explorado à luz da teoria de Bardin (2009). Com o estudo do material emergiram as seguintes categorias: 1- Termos empregados pelos estudantes em contextos do cotidiano, 2- Conceitos que envolvem experimentos simples, 3Equipamentos de laboratório.

O quadro 1, apresenta o resultado da catalogação dos termos que já possuem sinais conforme o dicionário e sua categorização, a saber:

\begin{tabular}{|l|l|}
\hline Categorias & Verbetes \\
\hline $\begin{array}{l}\text { Termos empregados pelos estudantes em contextos } \\
\text { do cotidiano }\end{array}$ & $\begin{array}{l}\text { Aço, açúcar, água, álcool, alumínio, diamante, } \\
\text { ferro, borracha, fósforo, gasolina, ouro, detergente, } \\
\text { prata, sabão, vidro, vinagre, vinho, cubo de gelo, } \\
\text { gelo e imã, atração, esfera, material, odor, oval, } \\
\text { pesado, pó, quente, veneno, calor, frio, inodoro, } \\
\text { química, cor, aroma, doce, eletricidade, fétido, } \\
\text { força, kilograma, litro e pigmento. }\end{array}$ \\
\hline Conceitos que envolvem experimentos simples & $\begin{array}{l}\text { Absorver, filtrar, aumentar, banhar, condensar, } \\
\text { congelar, modificar, aspirar, atear fogo, derreter, } \\
\text { fogo, misturar, modificar, gelar, gotejar e injetar. }\end{array}$ \\
\hline Equipamentos de Laboratório & $\begin{array}{l}\text { Bomba, microscópio, óculos de proteção e bomba } \\
\text { de ar. }\end{array}$ \\
\hline
\end{tabular}

Quadro 1: Catalogação de verbetes no Dicionário Enciclopédico Ilustrado Fonte: Autoria Própria.

O Dicionário Enciclopédico Ilustrado Trilíngue, possui ampla utilização na literatura, sendo que diversos autores realizaram o levantamento desses termos dicionarizados, como no trabalho de Souza e Silveira (2011). Contudo, o foco dessa pesquisa centrou-se em obter as categorias e a partir delas analisar àquela que se refere a equipamentos de laboratório, verificando quais sinais já se encontram disponíveis, para então desenvolver sinais para outros equipamentos.

Com base nisso, foi efetuado um levantamento de termos no roteiro de aulas práticas e comparou-se com os sinais já dicionarizados. Ao qual foram selecionados quatro verbetes (Balança analítica; Bureta; Becker; Pipeta) de uso recorrente no roteiro para serem sinalizados. 
A partir disso, observa-se na figura 1 o sinal desenvolvido para a balança analítica, que de acordo com a concepção do estudante surdo, significa o ato de colocar o corpo sobre a balança.

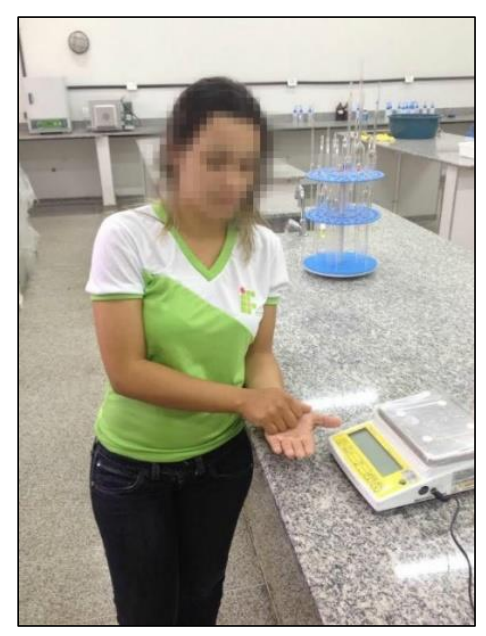

Figura 1: Sinal para a balança analítica Fonte: Autoria Própria.

A elaboração desse sinal vem ao encontro à discussão levantada por Lacerda (1998), no qual as práticas que estimulam o Bilinguismo propiciamum ambiente efetivo para que a Língua de Sinaisseja utilizada no âmbito educacional, ou seja, com a elaboração do sinal, permite a interação entre docente, interprete e o estudante surdo, contribuindo dessa forma para o processo de ensino e de aprendizagem.

De acordo com Machado e Moura (1995), a construção de conceitos científicos em sala de aula, especialmente em relação aos experimentos químicos é uma tarefa árdua com discentes surdos e ouvintes, uma vez que os fenômenos de compreensão da Química encontram-se no nível submicroscópico.

Sobre isso, Johnstone (1982) ressaltou que todos os estudantes devem navegar entre dois diferentes níveis de conhecimento, uma vez que o conhecimento químico se encontra no nível submicroscópico ou explanatório, em que os fenômenos são explicados. Contudo os discentes não compreendem esse nível sendo necessário, transpor para o macroscópico que é descritivo e funcional, pois neste se dá o ciclo de experimentação, observação e descrição dos fenômenos. Sendo assim, o processo de elaboração dos diversos sinais permiteque estudantes surdos possam compreender a Química como Ciência experimental.

Na figura 2 apresenta-se o sinal desenvolvido para a bureta que de acordo, com a concepção do estudante surdo, representa a configuração manual utilizada para segurar e operar o equipamento. 


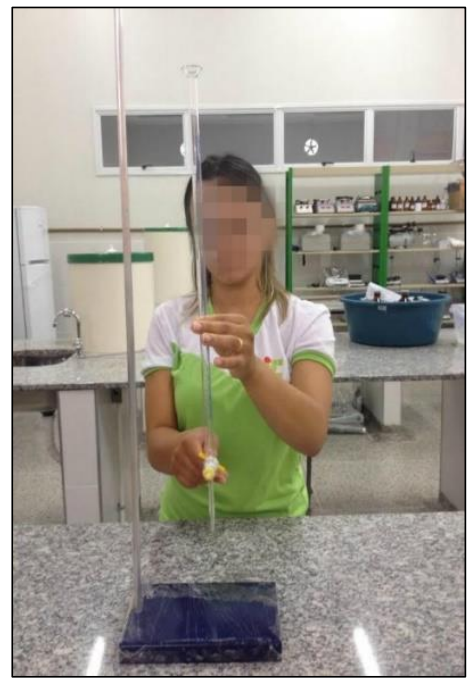

Figura 2: Sinal para a bureta Fonte: Autoria Própria.

O processo de desenvolvimento dos sinais é lento, pois o estudante surdo utiliza de seus conhecimentos interiorizados ao longo de sua vida escolar, assim como, a sua perspectiva cultural para a criação do termo. Apesar disso, esse processo constitui uma ferramenta motivadora e de intercâmbio de saberes entre o discente surdo, intérprete e o professor.

Com isso, ressalta-se que a criação dos sinais apresenta potencial para o docente investigar a compreensão de temas trabalhados no decorrer das disciplinas de Química Geral e Experimental I, na qual destacam-se os conteúdos de processos químicos, reações químicas, propriedades químicas dos elementos e solubilidade de substâncias polares e não polares.

A figura 3 apresenta o sinal desenvolvido para o Becker que retrata a posição de segurar está vidraria e a conformação característica desse instrumento.

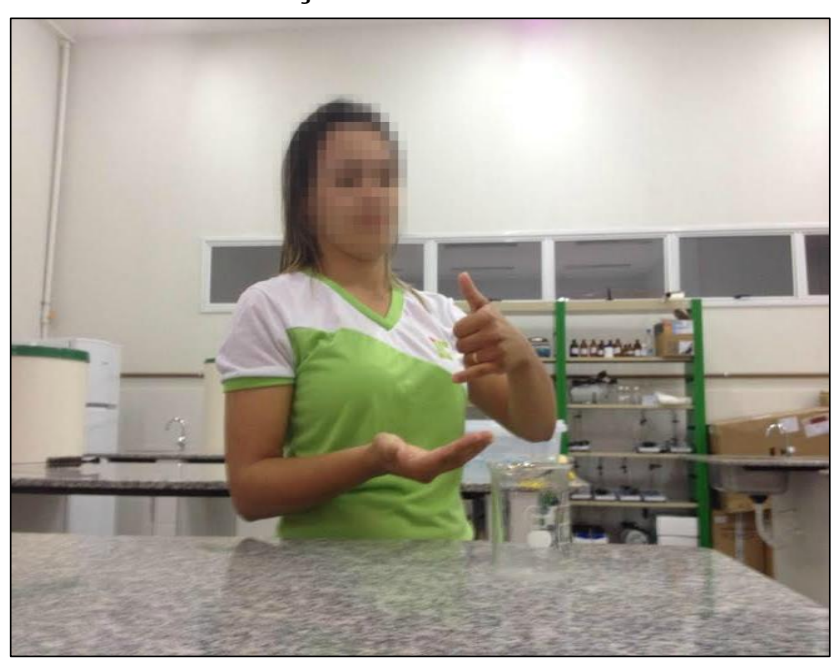

Figura 3: Sinal para o Becker Fonte: Autoria Própria. 
Dessa forma, o desenvolvimento dos sinais pode propiciar o aprendizado dos discentes surdos que utilizam a Libras como sua primeira língua, para a interação com os colegas de classe e com os docentes. Somando-se a isso esses estudantes podem utilizar a Língua Portuguesa na modalidade escrita para resolver as equações e cálculos estequiométricos que são comumente empregados nos laboratórios de Química, ou seja, a linguagem apresenta potencial para auxiliar no processo de formação dos conceitos científicos.

Nesse víeis, Vygotsky (1984) demonstrou que a formação dos conceitos científicos, surge no processo de solução de situações-problemas e o aprendizado emerge como resultado dessa solução. O desenvolvimento da linguagem científica está voltado ao contexto escolar e sua importância para o desenvolvimento da aprendizagem. Em outras palavras a construção desses conceitos parte de uma premissa que tem como meta o desenvolvimento cognitivo, a partir de operações mentais que o aluno desenvolve durante a criação dos sinais, contribuindo com isso para o processo de aprendizagem.

O quarto sinal desenvolvido foi referente à pipeta que possui diversas aplicações, como medir o volume de determinada solução. Na figura 4, visualiza-se o sinal desenvolvido para esta vidraria do laboratório que representa a posição do polegar para segurar a pêra e a disposição vertical no qual escorre o líquido.

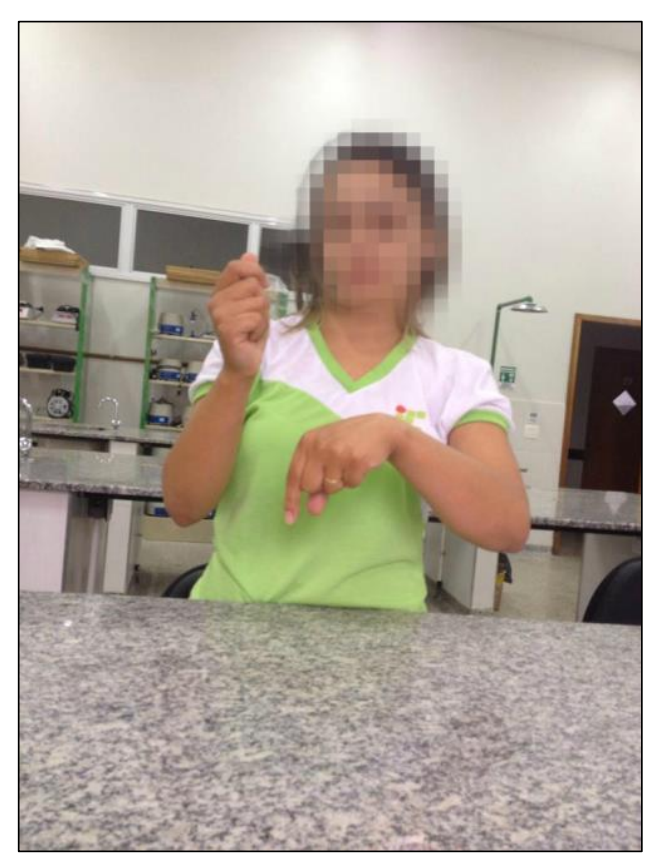

Figura 4: Sinal para a pipeta.

Fonte: Autoria Própria. 
'Pode-se acrescentar ainda que a criação de sinais é um processo construtivo, pois demanda identificar a zona de desenvolvimento real do estudante surdo que deve estar incluído no meio educacional, por meio de práticas bilíngues que permeiam a organização cognitiva (LEITE; LEITE, 2012).

Entretanto, embora se reconheça aqui a relevância para a educação dos surdos, o uso de práticas bilíngues, ainda são escassas. E tratando-se da elaboração de sinais para o Ensino de Química, temos à complexidade encontrada na criação destas estruturas que interferem na organização dos conceitos para alunos surdos.

Nesse ínterim o docente deve integrar-se ao meio cultural do surdo para que, articulado com a sua formação acadêmica, propicie as bases necessárias para a evolução conceitual dos estudantes surdos em relação aos conteúdos curriculares de Química.

Com a elaboração da categoria, instrumentos de laboratórios forampossíveis observar a sua defasagem de sinais em LIBRAS, o que preconiza a carência de estudos bilíngues, que visam à criação de sinais para tal classe de verbetes.

Nesse contexto, Reis (2015) acrescenta a essa discussão que os sinais para termos científicos, devem contemplar a utilização de imagens e a utilização de recursos experimentais disponíveis para facilitar o ensino em LIBRAS.

Dessa forma, para a Educação Química bilíngue a utilização da Língua Brasileira de Sinais deve ser incentivada como a primeira língua dos surdos, pois permite que sejam agentes ativos no processo educacional.

\section{Considerações finais}

Com o desenvolvimento da pesquisa foi possível perceber que a Química possui um campo de termologias em Língua Brasileira de Sinais ainda pouco explorados, sendo que as atividades de laboratório constituem uma vertente com sinais incipientes.

Apesar dos documentos oficiais indicarem que a Educação Bilíngue seja implantada em escolas públicas, ainda encontramos lacunas nesse processo, visto que o Decreto $\mathrm{n}^{\mathrm{o}} 5.626$, de 22 de dezembro de 2005 e o documento da Política Nacional de Educação Especial na Perspectiva da Educação Inclusiva (2007), não indicam como as práticas pedagógica bilíngues devem ocorrer, portanto propõem-se como reflexão pela ação no qual o aluno surdo é estimulado a buscar novos conhecimentos por meio da pesquisa como prática educativa. Além disso, o desenvolvimento de sinais impulsiona o 
processo de desenvolvimento cognitivo e a aprendizagem passa então a ser visto como uma interação entre o indivíduo e meio social que o permeia.

Vale destacar que a criação de sinais para auxiliar a Educação Química é um trabalho de longa duração tendo em vista que o processo depende dos organizadores prévios de cada estudante surdo, portanto pode variar em cada indivíduo. Apesar do sinal ser construído pelo discente surdo é importante o papel da interação do tripé: professor, interprete e o estudante para que posteriormente os sinais sejam padronizados, e para que não ocorram distorções conceituais relativos à compreensão de determinado sinal.

Sendo assim, os objetivos foram contemplados com a proposta de desenvolvimento dos sinais para a balança analítica, bureta, becker e a pipeta que podem auxiliar os estudantes surdos na disciplina de Química, no nível superior e em escolas da educação básica que utilizem laboratórios didáticos. Cabe ressaltar que esses sinais precisam ser validados pela comunidade surda.

\section{Referências}

AZEVEDO, M. C. P. S. Ensino por investigação: problematizando as atividades em sala deaula. In: CARVALHO, A. M. P. (Org.). Ensino de ciências: unindo a pesquisa e a prática. SãoPaulo: Pioneira Thomson Learning, 2004. p.19-33.

BARDIN, L. Análise de Conteúdo. 4.ed. Lisboa: Edições 70, 2009.

BOTELHO, P. Segredos e silêncios na interpretação dos surdos. Belo Horizonte: Autêntica, 1998.

BRASIL. MEC. Parâmetros Curriculares Nacionais: Ensino Médio. Brasília:

MEC/SEMTEC, 1999.

BRASIL. Dispõe sobre a Língua Brasileira de Sinais - Libras e dá outras providências. Lei $\mathrm{n}^{\circ}$ 10.436, 24 de abril de 2002, Brasília, DF.

BRASIL. Regulamenta a Lei ${ }^{\circ} \mathbf{1 0 . 4 3 6}$, de 24 de abril de 2002, que dispõe sobre a Língua Brasileira de Sinais- Libras, e o art. 18 da Lei ${ }^{\circ} 10.098$, de 19 de dezembro de 2000. Decreto $\mathrm{N}^{\circ}$ 5.626, de 22 de dezembro de 2005.

BRASIL. Política Nacional de Educação Especial na Perspectiva da Educação Inclusiva. Portaria Ministerial n. 555, de 5 de junho de 2007. LEX: MEC/SEESP, Brasília, 12p. junho/outubro, 2007.

CAPOVILLA, F. C.; RAPHAEL, W. D.; Dicionário enciclopédico Ilustrado trilíngue da Língua de Sinais Brasileira. Vol. 1 e vol. 2, São Paulo: EDUSP, 2009.

FERNANDES, E. Linguagem e surdez. Porto Alegre: Artmed, 2003.

FERNANDES, E. (Org.). Surdez e bilinguismo. Porto Alegre: Mediação, 2005. 
FERREIRA, L. H.; HARTWIG, D. R.; OLIVEIRA, R. C. de. Ensino experiemental de Química: Uma abordagem investigativa contextualizada. Química Nova na Escola, São Paulo, v.32, n.2, p. 101-106, 2010.

FAULSTICH, E. Dicionário enciclopédico ilustrado trilingüe da língua de sinais brasileira. Perspectiva, Florianópolis, v.24. n. Especial, p. 197-201, 2006.

GARCIA, V, M. et al. O desenvolvimento da argumentação e da linguagem científica por graduandos em química mediante a produção textual. In: ENCONTRO NACIONAL DE ENSINO DE QUÍMICA, 16., 2012. Salvador. Anais... Salvador: ENEQ, 2012. p. 1-12.

GIORDAN, M. O papel da Experimentação no ensino de ciências. Química Nova Na Escola, São Paulo, n.10, p. 43-49, nov. 1999.

GÓES, M.C.R. Linguagem, surdez e educação. Campinas: Autores Associados,1996.

GUEDES, S. de S. Experimentação no ensino de ciências: atividades problematizadas e interação dialógicas. 2010. 150f. Dissertação (Mestrado em Ensino de Ciências) - Instituto de Ciências Biológicas, Instituto de Física, Instituto de Química Universidade de Brasilía, Brasília, 2010.

GUIMARÃES, C. C. Experimentação no Ensino de Química: Caminhos e Descaminhos Rumo à Aprendizagem Significativa. Química Nova Na Escola, São Paulo, v.31, n.3, p. 198-202, 2009.

HODSON, D. Experiments in Science and Science Teaching. Educational Philosophy and Theory, v. 20, n. 2, p. 53-66, 1988.

IFMS: Instituto Federal de Mato Grosso do Sul. Projeto pedagógico do curso Licenciatura em Química, 2016. Disponível em: <http://www.ifms.edu.br/centrais-de-conteudo/documentosinstitucionais/projetos-pedagogicos/projetos-pedagogicos-dos-cursos-de-graduacao/projetopedagogico-do-curso-superior-licenciatura-quimica-coxim.pdf>. Acesso em: 20 out. 2017.

JOHNSTONE, A. H. Macro and Microchemistry. The School Science Review, [s.1.], v. 64, n. 227, p. 377-379, 1982.

LACERDA, C. B. F. de. Um pouco da história das diferentes abordagens na educação dos surdos. Caderno Cedes, Campinas, v.19, n.46, p. 68-80, 1998.

LACERDA, C. B. F. de. A Inclusão Escolar De Alunos Surdos: O Que Dizem Alunos, Professores e Intérpretes Sobre Esta Experiência. Caderno Cedes, Campinas, v. 26, n. 69, p. 163-184, 2006.

LAUXEN, A. A. et al. A atividade experimental na construção do conhecimento científico: Um debate mediado-uma articulação possível. Revista Debates em Ensino de Química, v. 3, n.2 (especial), p. 5-18, 2017.

LEITE, É, R, O, R; LEITE, B, S. O Ensino de Química para Estudantes Surdos: A Formação dos Sinais. In: ENCONTRO NACIONAL DE ENSINO DE QUÍMICA, 16., 2012, Salvador. Anais... Salvador: ENEQ, 2012. p. 1-9.

LIMA, A, de, A. NÚÑEZ, I, B. Reflexões acerca da natureza do conhecimento químico: Uma investigação na formação inicial de professores de química. Revista Brasileira de Pesquisa em Educação em Ciências, Belo Horizonte, v. 11, n.3, p. 209-229, 2011. 
MACHADO, A, H; MOURA, A, L, A. Concepções sobre o papel da linguagem no processo de elaboração conceitual em Química. Química Nova na Escola, São Paulo, n. 2, p. 27-30, nov. 1995.

QUADROS, R, M. SCHMIEDT, M, L, P. Ideias para Ensinar Português para Alunos Surdos. Brasília: MEC/SEESP, 2006.

REIS, E, S. O ensino de química para alunos surdos: Desafios e práticas dos professores e interpretes no processo de ensino e aprendizagem de conceitos químicos traduzidos para Libras. 2015. 135f. Dissertação (Mestrado em Ensino de Ciências e Matemática) - Centro de Ciências, Universidade Federal do Ceará, Fortaleza, 2015.

SOUSA, S. F.; SILVEIRA, H, E.; Terminologias Químicas em Libras: A Utilização de Sinais na Aprendizagem de Alunos Surdos. Química Nova Na Escola, São Paulo, v.33, n. 1, p. 37-46, 2011.

STUMPF, R, M.; QUADROS, R, M.; Tradução e interpretação da Língua Brasileira de Sinais: Formação e Pesquisa. Cadernos de Tradução, Florianópolis, v. 2, n. 6, p. 166-205, 2010.

TAVEIRA, C, C. Por uma Didática da invenção surda: prática pedagógica nas escolas-piloto de educação bilíngue no município do Rio de Janeiro. 2014. 365f. Tese (Doutorado em Educação) - Departamento de Educação do Centro de Teologia e Ciências Humanas, Pontifícia Universidade Católica do Rio de Janeiro, Rio de Janeiro, 2014.

VARGAS, J.S. Elaboração de uma proposta de sinais específicos para os conceitos de massa força e aceleração em Libras. 2014. 119f. Dissertação (Mestrado em Ensino de Ciências) - Instituto de Física, Universidade Federal De Mato Grosso do Sul, Campo Grande, Mato Grosso do Sul, 2014.

VYGOSTSKY, L.S. A Formação social da Mente. 2. ed. São Paulo: Martins Fontes. 1984.

Recebido em: 05 de março de 2018.

Aceito em: 30 de abril de 2018. 